\title{
ANALISIS DAN PERANCANGAN JARINGAN KOMPUTER UNTUK IMPLEMENTASI SISTEM INFORMASI PADA WINDOWS SERVER 2016 MENGGUNAKAN INTERNET DAN INTRANET DI UNIVERSITAS TEKNOLOGI SUMBAWA
}

\author{
Rodianto $^{\text {1), Ahmad Juliansyah }}{ }^{2)}$ \\ ${ }^{1)}$ Dosen Informatika Universitas Teknologi Sumbawa \\ 2) Mahasiswa Informatika Universitas Teknologi Sumbawa \\ email : ${ }^{1)}$ rodianto@uts.ac.id,, 2) ahmadjuliansyah28@gmail.com
}

\begin{abstract}
Abstrak
Jaringan internet dan intranet merupakan fasilitas yang dipergunakan untuk menunjang proses pendidikan, khususnya proses pembelajaran. Universitas Teknologi Sumbawa (UTS) merupakan salah satu Perguruan Tinggi swasta yang ada di Kabupaten Sumbawa, Provinsi Nusa Tenggara Barat. Server merupakan perangkat pusat data yang dimiliki kampus untuk mendukung kinerja civitas akademika dalam implementasi sistem informasi. Selain itu, saat ini UTS masih terus melakukan pengembangan jaringan kabel dan nirkabel yang dapat mendukung implementasi sistem dengan pengadaan peralatan teknologi informasi lainnya. Penelitian ini bertujuan untuk menganalisis dan merancang jaringan komputer untuk implementasi sistem pada windows server 2016 menggunakan internet dan intranet Studi Kasus Universitas Teknologi Sumbawa. Metode yang digunakan untuk pengembangan jaringan yaitu Prepare, Plan, Design, Implement, Operate, Optimize (PPDIOO). Pengujian berhasilnya implementasi sistem informasi dilakukan melalui Implement. Instrumen teknik pengumpulan data pada penelitian ini menggunakan studi pustaka, observasi, dan wawancara. Hasil akhir dari penelitian ini adalah sistem informasi pada komputer server dapat berjalan melalui internet dan intranet yang berguna untuk menunjang kinerja civitas akademika universitas.
\end{abstract}

Kata kunci: Jaringan, Analisis, Perancangan, Implementasi, Universitas Teknologi Sumbawa, Server, PPDIOO.

\begin{abstract}
Internet and intranet network is a facility used to support the educational process, especially the process of learning. Sumbawa University of Technology (UTS) is one of the private universities in Sumbawa, West Nusa Tenggara Province. The server is a device owned by the campus data center to support the performance of the academic community in the implementation of information systems. In addition, the UTS is currently still reviewing the development of wired and wireless networks to support the implementation of the procurement system with other information technology equipment. This study aimed to analyze and design computer networks for the implementation of the system on windows server 2016 using the internet and intranet Case Studies University of Technology Sumbawa. The method used for the development of a network that is Prepare, Plan, Design, Implement, Operate, Optimize (PPDIOO). Successful testing implementation conducted through Implement information systems. Instrument data collection techniques in this study using literature study, observation, and interviews. The end result of this research is on the server computer information systems can be run via the internet and intranet useful to support the performance of the academic community of the university.
\end{abstract}

Keywords: Network, Analysis, Design, Implementation, University of Technology Sumbawa, Server, PPDIOO.

\section{PENDAHULUAN}

Universitas Teknologi Sumbawa (UTS) merupakan salah satu Perguruan Tinggi Swasta yang ada di Kabupaten Sumbawa, Provinsi Nusa Tenggara Barat. UTS berdiri sejak tanggal 13 Maret 2013 berdasarkan keputusan Menteri Pendidikan dan Kebudayaan Republik Indonesia No: 65/E/O/2013, berlokasi di Jalan Raya Olat Maras, Dusun Batu
Alang, Desa Leseng, Kecamatan Moyo Hulu. Memiliki sarana teknologi informasi yang memadai diantaranya server, jaringan internet, dan sistem informasi yang berasal dari karya alumni, mahasiswa dan developer luar untuk menunjang kinerja dari civitas akademika kampus.

Sarana teknologi informasi di UTS sangat memadai untuk mendukung implementasi sistem 
informasi. Akan tetapi permasalahan yang terjadi di UTS adalah, pada implementasi dari sistem tersebut agar dapat digunakan interaktif oleh kampus, harus berbasis online, sehingga dibutuhkan sebuah hosting domain dari pihak ketiga. Serta spesifikasi dan bentuk server, untuk implementasi sistem tersebut masih bersifat perangkat personal komputer yang memiliki keterbatasan. Hal ini mengakibatkan fungsi serta peran dari perangkat teknologi jaringan komputer di kampus tidak sepenuhnya digunakan. Sementara UTS memiliki fasilitas jaringan internet indihome, astinet dan IP public serta komputer server yang sangat memadai untuk difungsikan dalam implementasi sistem informasi tersebut.

Berdasarkan uraian permasalahan diatas, solusi yang ditawarkan penulis pada penelitian ini adalah "Analisis dan Perancangan Jaringan Komputer untuk Implementasi Sistem pada Windows Server 2016 Menggunakan Internet dan Intranet di Universitas Teknologi Sumbawa". Dimana hasil dari penelitian ini dapat membantu pihak kampus serta unit IT support untuk implementasi sistem-sistem informasi pada server data pusat yang dapat berjalan pada jaringan internet dan intranet kampus, sehingga dapat diakses dan digunakan seluruh civitas akademika Universitas Teknologi Sumbawa.

\section{TINJAUAN PUSTAKA}

Beberapa literatur yang digunakan sebagai pedoman dan acuan untuk implementasi sistem informasi pada windows server 2016 menggunakan jaringan internet dan intranet di Universitas Teknologi Sumbawa yaitu.

Perancangan infrastruktur jaringan komputer untuk mendukung implementasi sistem informasi. Penelitian dilakukan di Universitas Teknologi Sumbawa dengan tujuan untuk mendukung hadirnya aplikasi dan sistem informasi dengan infrastruktur jaringan yang memadai. Kategori penelitian kualitatif yang bersifat deskriptif dimana framework yang digunakan adalah Network Development Life Cycle (NDLC). Hasil dari penelitian tersebut adalah simulasi skenario yang menunjukan bahwa dengan jaringan komputer yang terintegrasi menggunakan media kabel (simulasi kabel) memiliki page response time, object response time, response time $d b$ entryquery tercepat dan delay terendah, sehingga akan memudahkan dalam pengembangan aplikasi-aplikasi sistem informasi pada lingkup Universitas Teknologi Sumbawa. [4]

\section{METODE PENELITIAN}

Adapun metode pengumpulan data, gambaran umum objek penelitian dan metode pengembangan jaringan adalah sebagai berikut:

\section{Metode Pengumpulan Data}

Adapun metode pengumpulan data yang digunakan dalam pembuatan penelitian skripsi ini adalah studi kepustakaan, observasi, wawancara dan dokumentasi. Berikut penjabaran dari metode pengumpulan data yang digunakan sebagai berikut:

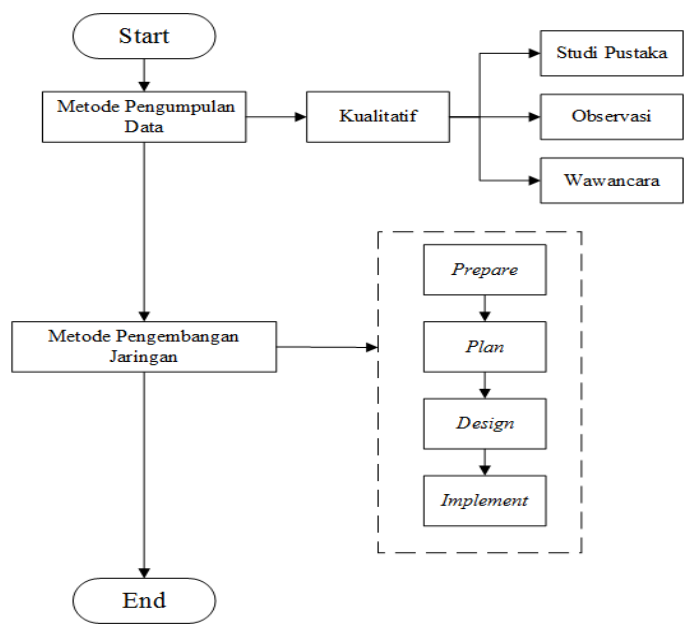

Gambar 1. Flowchart Kegiatan.

a. Studi Kepustakaan

Merupakan metode pengumpulan data yang diperoleh melalui studi kepustakaan (literature) yaitu dengan mencari bahan dari internet, jurnal dan tesis yang sesuai dengan objek yang diteliti..

b. Observasi

Merupakan metode pengumpulan data yang diperoleh dari lapangan dengan cara terjun langsung ke lapangan dan mencari data yang ada di UTS.

c. Wawancara

Merupakan metode pengumpulan data yang diperoleh langsung dari narasumber atau orang yang dapat dipercaya yaitu pihak unit IT yang ada di UTS.

\section{Metode Pengembangan Jaringan}

Adapun metode yang digunakan dalam pengembangan jaringan adalah metode prepare, plan, design, implement, operate, and optimize (PPDIOO), yang dibatasi hanya sampai implement.

a Prepare 
Prepare merupakan fase persiapan hasil analisis dari sisi perangkat keras dan perangkat lunak jaringan, sistem-sitem informasi yang akan digunakan dalam penelitian berada dalam kondisi terbaik pada ruang IT serta topologi jaringan yang ada di Universitas Teknologi Sumbawa.

b Plan

Plan merupakan fase perencanaan khusus, dengan modal yang berasal dari input fase prepare, dimana didapatkan hasil analisis kebutuhan yang akan menjadi acuan penulis dalam perencanaan pengembangan jaringan yang ada di Universitas Teknologi Sumbawa.

\section{c Design}

Design merupakan fase perancangan jaringan yang berasal dari hasil fase sebelumnya yaitu Plan. Pada fase ini penulis akan melakukan perancangan jaringan secara detil yang harus dilakukan ketika implementasi. Mulai dari perangkat jaringan yang akan digunakan sampai gambaran lengkap dari konfigurasi di ruang IT Universitas Teknologi Sumbawa

\section{d Implement}

Design merupakan fase perancangan jaringan yang berasal dari hasil fase sebelumnya yaitu Plan. Pada fase ini penulis akan melakukan perancangan jaringan secara detil yang harus dilakukan ketika implementasi. Mulai dari perangkat jaringan yang akan digunakan sampai gambaran lengkap dari konfigurasi di ruang IT Universitas Teknologi Sumbawa.

\section{Gambaran Umum Objek Penelitian}

Universitas Teknologi Sumbawa memiliki dua buah komputer server dengan spesifikasi hardware dan software yang berbeda, dan tiga buah modem internet yaitu indihome $100 \mathrm{Mbps}$ wilayah gedung orange, indihome $100 \mathrm{Mbps}$ dan astinet 5 Mbps dengan 5 buah IP public di wilayah gedung rektorat, serta sistem informasi karya mahasiswa yang telah digunakan

\section{HASIL DAN PEMBAHASAN}

\section{Prepare}

Dari hasil analisis perangkat jaringan, software, sistem infomasi serta topologi jaringan sebelumnya, yang ada di UPT IT Universitas Teknologi Sumbawa, maka dapat disimpulkan persiapan yang akan dilakukan adalah sebagai berikut :

1. Pengembangan jaringan 2019
Berdasarakan hasil rapat kerja akhir tahun universitas dalam pengembangan teknologi informasi dan jaringan yang akan dilakukan pada tahun 2019 adalah :

a. Penambahan perangkat modem jaringan internet dan accses point dalam mengakomodasi pengguna internet kampus yang semakin banyak.

b. Penyatuan jaringan antara dua wilayah yang berbeda yaitu wilayah gedung orange dan gedung rektorat.

c. Mengoptimalkan perangkat server untuk data center sistem informasi.

2. Persiapan sistem informasi

Berikut beberapa daftar dari sistem informasi yang ada di UPT IT Universitas Teknologi Sumbawa.

\begin{tabular}{|c|l|l|}
\hline No. & \multicolumn{1}{|c|}{ Tabel 3.1 daftar sistem informasi } \\
\hline 1 & PDDIKTI Feader & PDDIKTI \\
\hline 2 & SISTER & RISTEKDIKTI \\
\hline 3 & SIPAPI & Mahasiswa \\
\hline 4 & SIMAMI & Mahasiswa \\
\hline 5 & $\begin{array}{l}\text { E-Monev } \\
6\end{array}$ & $\begin{array}{l}\text { CBT }- \\
\text { Online Test }\end{array}$ \\
\hline
\end{tabular}

3. Penggunaan internet

Berdasarkan laporan data traffic dari penggunaan internet di Universitas Teknologi Sumbawa semakin tinggi dengan bertambahnya karyawan dan mahasiswa. Berikut aturan penggunaan internet universitas.

4. Topologi Universitas Teknologi Sumbawa

Berdasarkan dari hasil analisis yang telah dilakukan, jaringan yang ada di Universitas Teknologi Sumbawa memiliki jaringan yang terpisah antara dua wilayah yaitu topologi jaringan rektorat area dan topologi jaringan orange area.

Berdasarkan hasil analisis yang telah dijabarkan, maka dapat disimpulkan kebutuhan dalam penelitan ini adalah sebagai berikut :

1. Perangkat server terpusat hanya pada ruang IT wilayah rektorat yang terhubung ke seluruh jaringan kampus.

2. Perancangan topologi jaringan untuk seluruh wilayah UTS dalam realisasi penyatuan jaringan. 
3. Seluruh sistem informasi yang ada, dapat terimplementasi pada sebuah perangkat server yang bersifat personal komputer.

4. Seluruh sistem informasi berjalan di internet dan intranet pada seluruh wilayah Universitas Teknologi Sumbawa.

\section{Plan}

Gambaran umum dari perencanaan jaringan yang akan dibuat unutk implementasi sistem informasi pada server dengan sistem operasi windows server 2016 pada Universitas Teknologi Sumbawa:

1. Realisasi penyatuan jaringan untuk implementasi system.

Dalam fase ini akan dilakukan perancangan jaringan yang akan diusulkan untuk implementasi sistem tersebut, dimana akan diawali dengan perancangan jaringan di ruang IT yang diperuntukan untuk lokasi utama sistem informasi, kemudian akan dibuatkannya perancangan jaringan untuk seluruh wilayah kampus, yang hanya difokuskan untuk client dalam mengakses sistem informasi tersebut menggunakan internet dan intranet dengan pusat yaitu ruangan IT wilayah rektorat.

2. Pembuatan partisi untuk sistem informasi pada perangkat server.

Pada Fase ini pembuatan partisi sistem informasi pada server bertujuan sebagai wadah pemisah sistem yang akan diimplementasikan pada server.

3. Pembuatan sistem jaringan pada perangkat server.

Pembuatan sistem jaringan pada server bertujuan untuk menghubungkan seluruh sistem informasi agar dapat berjalan di jaringan internet dan intranet kampus secara bersamaan dengan memanfaatkan 2 buah Port Lan yang pada server

4. Pembuatan akses sistem informasi pada Google Suite

Pada fase ini, perencanaan akses sistem informasi hanya diperuntukan untuk client dalam mengakases sistem informasi tersebut dengan memanfaatkan fitur dari Google Suite yang terintegrasi dengan Email korporasi kampus, dimana akan memudahkan civitas akademika UTS mengakses sistem tersebut.

\section{Design}

Pada fase ini akan dilakukan desain umum dari hasil perancangan topologi jaringan komputer di Universitas Teknologi Sumbawa, yang akan diusulkan untuk dapat diterapkan dalam mendukung implementasi seluruh sistem informasi yang ada, hingga sistem dapat berjalan secara intranet diseluruh wilayah Universitas Teknologi Sumbawa.

1. Topologi jaringan komputer pada ruang server

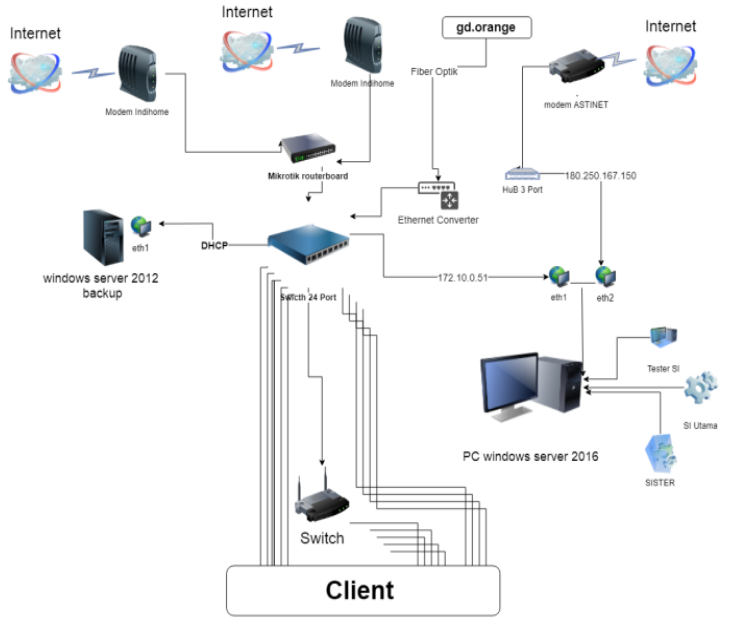

Gambar 2. Topologi Server UTS.

Dari hasil penelitian yang dilakukan pada UPT IT Universitas Teknologi Sumbawa menunjukan bahwa topologi yang digunakan pada perancangan topologi untuk jaringan server sistem informasi adalah topologi star. Pada topologi tersebut dilakukan penyatuan antara modem indihome dan modem astinet pada sebuah perangkat server dengan sistem operasi windows server 2016, yang dimana akan menjadi pusat dari implementasi seluruh sistem informasi yang ada di UTS.

2. Topologi jaringan komputer Universitas

Teknologi Sumbawa

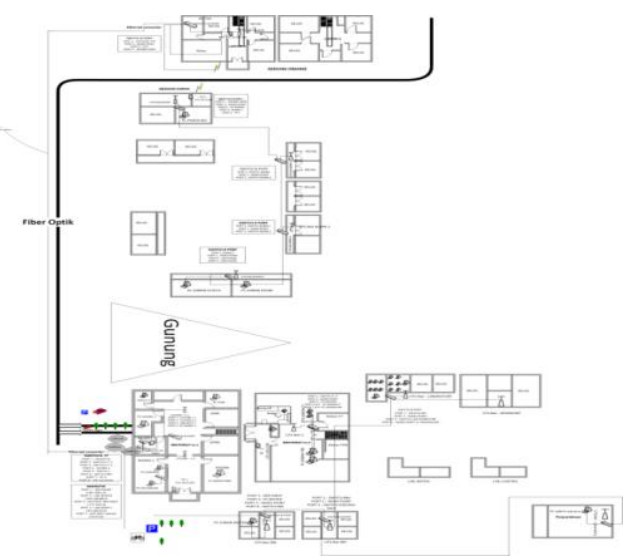

Gambar 3. Topologi Jaringan UTS 
Berdasarkan gambar diatas, akses sistem informasi melalui Intranet dapat dilakukan pada seluruh wilayah kampus yang terhubung melalui kabel dengan model DHCP Client serta ketika dapat terhubung secara local tidak menutup kemungkinan tetap bisa diakses melalui IP public atau akses internet yang diperuntukan untuk diluar area kampus, dengan catatan akan terpusat di server UPT IT dan jaringan antara orange dan rektorat terhubung melalui kabel optik secara local menggunakan Eth Converter.

3. Design web akses sistem informasi

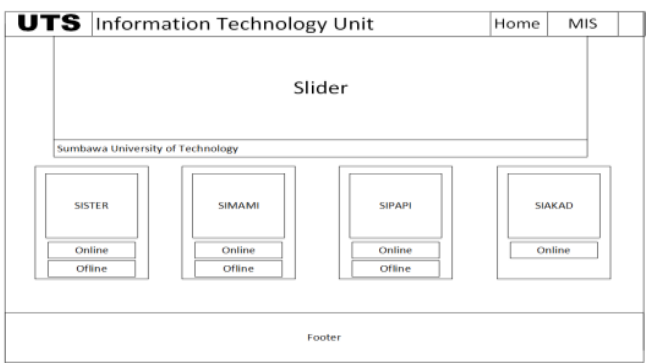

Gambar 4. Design web akses SI

Berikut adalah gambar dari perancangan website sistem informasi dari UPT IT yang diperuntukan untuk client agar dapat mengakses seluruh sistem informasi yang ada, dimana dari masing-masing fungsi button atau tombol SI telah diimplementasikan sistem informasi berdasarkan alamat IP address internet dan intranet yang diberikan oleh UPT IT di Univeristas Teknologi Sumbawa. Pembuatan Web Portal menggunakan fitur G-Suite yaitu Go $\neg$ ogle site yang telah teritegrasi dengan EMail korporasi kampus.

\section{Implement}

Pada fase ini dilakukan tahap implementasi dan konfigurasi jaringan pada server dan mikrotik, wadah seluruh sistem informasi yang pada server dapat berjalan.

$1 \quad$ Konfigurasi mikrotik

Dalam melakukan konfigurasi, peneliti menggunakan alat bantu berupa tool software yaitu winbox.

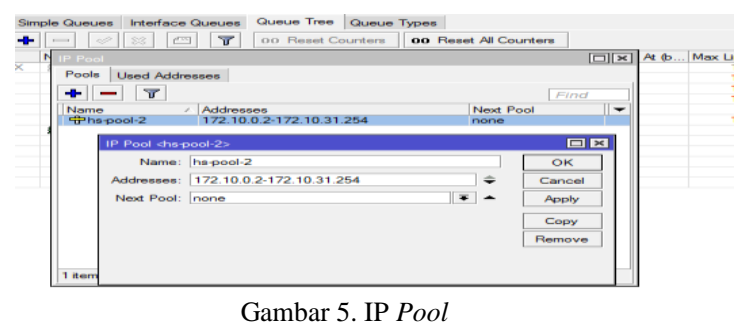

Berdasarkan gambar diatas jumlah address list dalam konfigurasi IP pool yang nantinya dapat mengakses sistem informasi adalah 172.10.0.2 sampai 172.10.31.254 jumlah address, menggunakan model secara DHCP.

\begin{tabular}{|c|c|c|c|c|c|c|c|}
\hline Servers & Server Profiles & Users & User Protiles & Active & \multirow[t]{2}{*}{ Hosts } & \multirow{2}{*}{\multicolumn{2}{|c|}{ IP Bindings }} \\
\hline $4 \square$ & 8 & & & & & & \\
\hline \multicolumn{2}{|l|}{ Name } & Session Time... & e... Idle Timeos & & Shared U... & Rate Limit & $(x / t x)$ \\
\hline \multicolumn{2}{|c|}{ Dosen \& Staff } & & & none & \multicolumn{3}{|c|}{$2128 \mathrm{k} / 128 \mathrm{k}$} \\
\hline \multicolumn{2}{|c|}{ QFree } & & & none & \multicolumn{3}{|c|}{$1128 \mathrm{k} / 128 \mathrm{k}$} \\
\hline \multicolumn{2}{|c|}{9 Students } & & & none & \multicolumn{3}{|c|}{$50128 \mathrm{k} / 128 \mathrm{k}$} \\
\hline \multicolumn{2}{|c|}{9 Tim IT } & & & none & \multicolumn{3}{|c|}{10} \\
\hline \multicolumn{2}{|c|}{ UUTS1 } & & & none & \multicolumn{3}{|c|}{$2128 \mathrm{k} / 128 \mathrm{k}$} \\
\hline \multicolumn{2}{|c|}{9 default } & & & none & & $2128 \mathrm{k} / 128 \mathrm{k}$ & \\
\hline
\end{tabular}

Gambar diatas menunjukan name group dari pengguna sistem informasi, serta aturan penggunaan Rate Limit pada winbox, tujuan dibuatkannya yang telah penilti konfigurasi pada tahap sebelumnya User profiles tersebut.

\section{Konfigurasi Server Manager}

Tahap pertama adalah konfigurasi IP address static dari modem indihome yang diberikan IT support untuk nantinya menjadi media akses SI intranet.

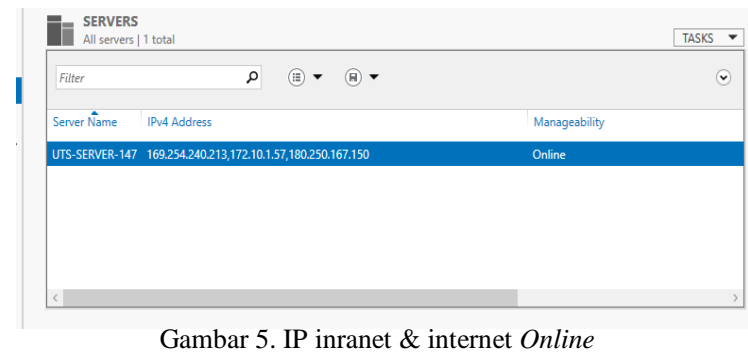

IP address dari indihome dan astinet yang telah di input secara static pada kedua etehernet di server yang menjadi backbone akses sistem informasi secara internet dan intranet telah online melalui windows server manager, telah online, atau siap digunakan seperti pada gambar diatas.

Kemudian tahap akhir menginstal seluruh fungsi fitur windows server manager agar dapat digunakan dengan online seperti pada gambar dibawah 


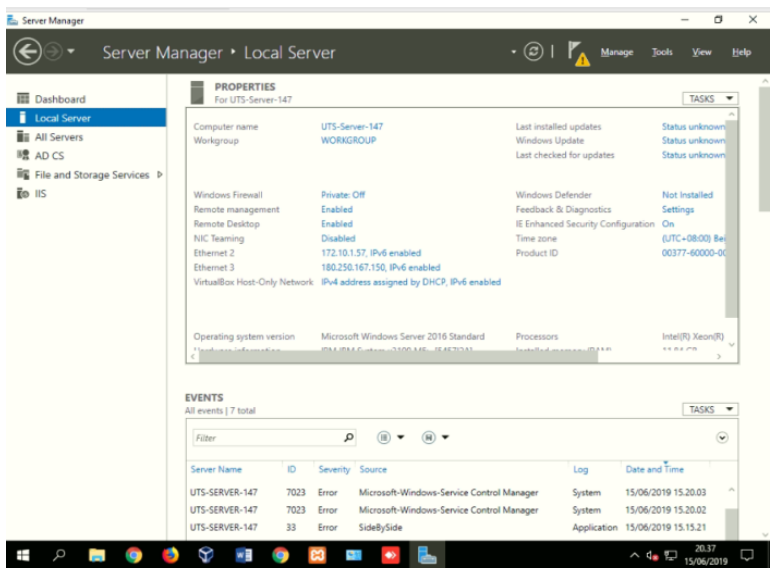

Gambar 6. Dashboard Win Server Manager

Pada gambar diatas, menunjukan bahwa implementasi untuk seluruh sistem informasi pada server telah siap diguanakan, dimana untuk eth1 adalah IP static dari modem indihome agar dapat diakses intranet dan eth2 adalah IP public dari modem Astinet untuk akses internet diluar wilayah kampus.

3 Instalasi Sistem informasi di Server

Selanjutkan dilakukan implementasi seluruh sistem informasi yang telah terintegrasi pada webserver menggunakan aplikasi xampp di folder htdoc.

\section{a. Membuat share folder}

Membuat share folder bertujuan agar file dapat diakses oleh klien-klien yang ada pada jaringan laboratorium komputer.

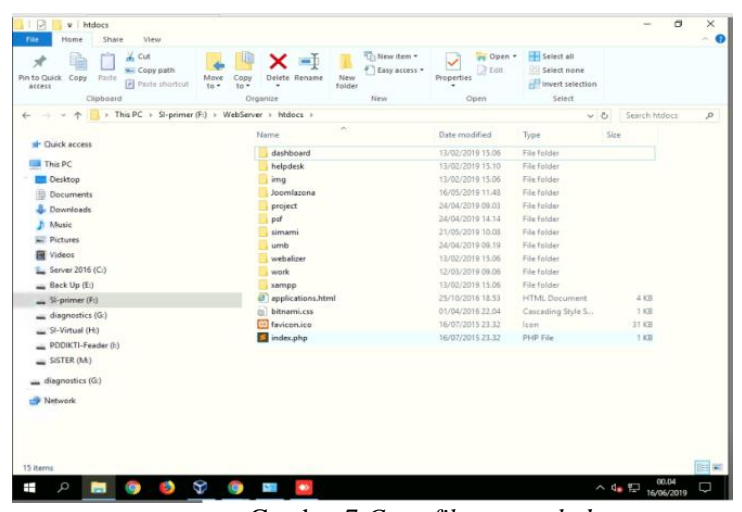

Gambar 7.Copy file system htdoc

Pada gambar diatas merupakan tampilan untuk folder web server utama pada PC server dimana pada tahap ini peneliti hanya menkopi sistem-sistem informasi yang akan diimplemementasi, tentunya sistem informasi yang telah terintegrasi atau menggunakan teknologi jaringan SSO.

b. Xampp server web

Kemudian dilakukan implementasi import database yang telah terintegrasi dari banyak sistem informasi yang terdapat pada webserver.

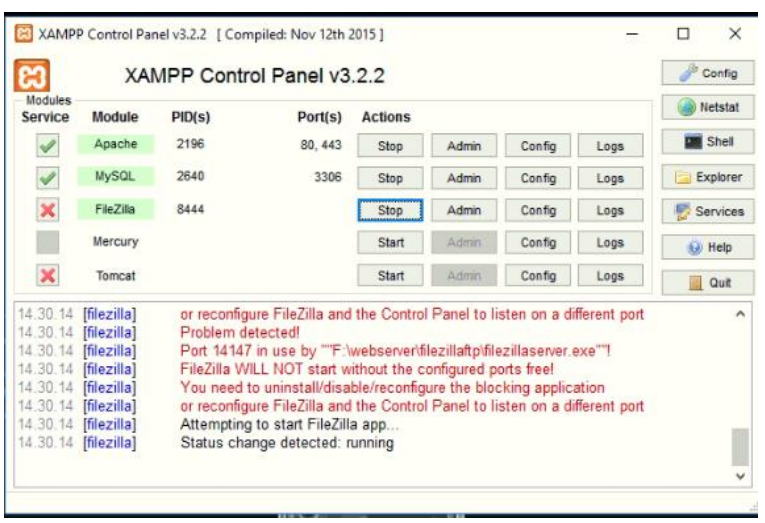

Gambar 8.Xampp

Seperti gambar diatas tahap selanjutnya adalah menjalankan fungsi pada XAMPP, yaitu Apache, MySQL, Filezilla pada XAMPP untuk mendukung implementasi sistem yang tidak hanya berjalan pada localhost akan tetapi mampu berjalan pada jaringan internet dan intranet kampus.

4 Implementasi seluruh SI pada web portal

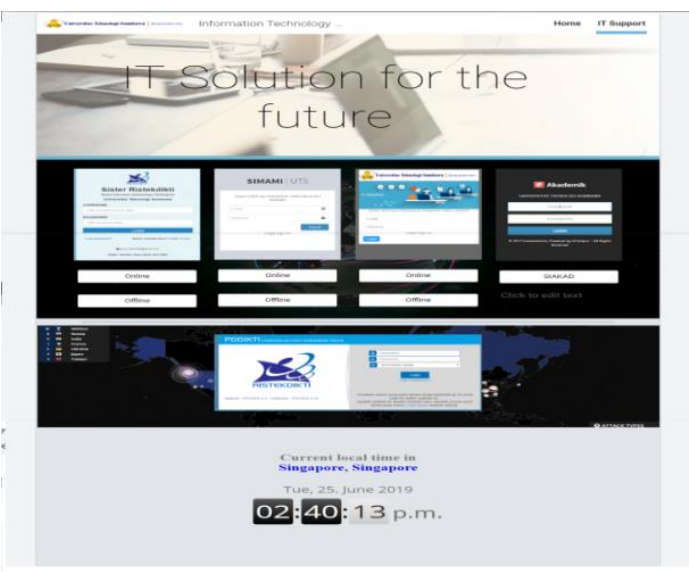

Gambar 7.Website akses SI

Pada fase ini adalah implementasi dari portal utama menggunakan IP address dari seluruh sistem informasi yang telah berhasil diakses secara internet dan intranet melalui website IT official yang, 
terintegrasi langsung dengan E-Mail korporasi kampus Universitas Teknologi Sumbawa.

\section{SIMPULAN DAN SARAN}

\section{Kesimpulan}

Kesimpulan yang dapat diambil dari skripsi ini yaitu dengan menggunakan metode pengembangan jaringan Prepare Plan Design Implement Operate Optimized (PPDIOO) analisis dan perancangan jaringan komputer untuk implementasi sistem yang berjalan di jaringan intranet akan lebih responsive menggunakan media Local Area Network (LAN) dan sistem juga mampu berjalan optimal di internet dengan menggunakan modem astinet dan IP Public.

Untuk implementasi sistem informasi pada windows server 2016 dapat diaplikasikan dengan memanfaatkan fitur Windows Server Manager 2016 sehingga sistem berjalan dengan sempurna di internet dan intranet pada Universitas Teknologi Sumbawa, dengan demikian penelitian ini dapat berkontribusi bagi seluruh civitas akademika dalam meningkatkan kinerja menggunakan sistem informasi di Universitas Teknologi Sumbawa.

\section{Saran}

Berdasarkan kesimpulan yang telah diuraikan diatas, adapun saran untuk pengembangan jaringan dalam implementasikan sistem informasi kedepannya yaitu dapat mengembangkan sistem informasi yang terintegrasi menggunakan teknologi SSO (Single Sign On) untuk seluruh sistem informasi yang ada di Universitas Teknologi Sumbawa.

\section{DAFTAR PUSTAKA}

[1] Arief, A. (2015). "Analisa Keamanan Jaringan Wireless menggunakan Radius Server pada Mikrotik". Skripsi. Program Studi Teknik Informatika Universitas Gadjah Mada. Yogyakarta.
[2] Behrouz A. (2003). Data Communications and Networking, Third Edition. McGraw-Hill. New York.

[3] Chaffey, D. (2011). E-Business and ECommerce Management Strategy, Implementation and Practice 5th Edition. London: Prentice hall Financial Times.

[4] Esabella, S. (2016). Perancangan Infrastruktur Jaringan Komputer Untuk Mendukung Implementasi Sistem Informasi Pada Universitas Teknologi Sumbawa, JurnalMatrik, vol. 16, no.1, pp. 1-2.

[5] Gufron. (2013). Perbaikan Perangkat Komputer. Bung Hatta University Press. Padang.

[6] Kurni, Asmunim. (2017) :Membangun Privilleges Pada Jaringan Komputer SMA Negeri 2 Boyolali Berbasis Active Directory Dengan Windows Server 2016 Enterprise. Laporan Tugas Akhir. Jurusan Teknik Elektro. Surakarta :Universitas Muhammadiyah Surakarta.

[7] Rainer Jr, R. Kelly \& Casey G. Cegielski. (2013). Introduction to Information Systemsfourt edition. Singapore: John Wiley and Sons Singapore pte. ltd.

[8] Sukaridhoto, Sritrusta. (2014). Jaringan Komputer, Edisi Pertama. Surabaya: Politeknik Elektronika Negeri Surabaya.

[9] Uji Muryanto, Prasetyo. (2011). "Implementasi Sistem Wireless Security dan Bandwdith Berbasis Radius Server dengan Mikrotik". Skripsi. Jakarta: Jurusan Teknik Informatika Universitas Islam Negeri Syarif Hidayatullah. 